\title{
Oxytetracycline as environmental contaminant in arable lands
}

\author{
Gianfranco Brambilla ${ }^{\mathrm{a}, *}$, Michele Patrizii $^{\mathrm{b}}$, Stefania Paola De Filippis ${ }^{\mathrm{a}}$, Giuseppe Bonazzi ${ }^{\mathrm{c}}$, \\ Paolo Mantovi ${ }^{\mathrm{c}}$, Davide Barchi ${ }^{\mathrm{d}}$, Luciana Migliore ${ }^{\mathrm{b}}$ \\ a ISS Environment Department, Rome, Italy \\ ${ }^{\mathrm{b}}$ University Tor Vergata, Department of Biology, Rome, Italy \\ ${ }^{\mathrm{c}}$ CRPA, Reggio Emilia, Italy \\ ${ }^{\mathrm{d}}$ Regione Emilia Romagna, Bologna, Italy
}

Received 2 July 2006; received in revised form 26 September 2006; accepted 6 November 2006

Available online 11 November 2006

\begin{abstract}
Oxytetracycline $(\mathrm{OXY})$ is a broad-range antimicrobial routinely used in pig production, at doses in the range of few $\mathrm{g} / \mathrm{kg}$ of medicated feed, during the weaning period. It could persist at ppm level in pig liquid manure that routinely is used for organic fertilisation. In the present work we describe a methodology to study OXY environmental fate in arable land where crops are cultivated for animal feeding purposes. A liquid-liquid extraction followed by metal chelate affinity chromatography was applied to environmental samples of manures and soils drawn within a case-control study. Extracts were then analysed by high performance liquid chromatography with UV/DAD detection, using a reverse phase column, and expressing the results as 4-epioxytetracycline epimer. Results indicate OXY is well retained at $\mathrm{mg} \mathrm{kg}^{-1}$ levels in soil exposed to contaminated pig manure fertilisation. Such compartment could constitute an abiotic reservoir for the systemic and/or for the external contamination of corn.
\end{abstract}

(C) 2006 Elsevier B.V. All rights reserved.

Keywords: Oxytetracycline; Manure contamination; Soil contamination

\section{Introduction}

Antimicrobial drugs utilized in intensive farming can impact on environmental compartments such as water and/or soil. Tetracyclines are among the most used in pig farming and previous studies demonstrated their persistence in manure and soil [1-3] and possible exposition of farmers during application of organic fertilizers to soil [4].

The debate on antibiotics environmental fate is reinforced by the concern on induction/selection of microbial resistance and by the possible ecosystem alterations, such as colonisation from fungi and yeasts, and inhibition of natural bacterial communities [5]. As regard tetracyclines, they have the highest capability to bind organic matter [6] if compared to other antimicrobials, and thus they usually locate in the top layer of soil, within the first $40 \mathrm{~cm}$ depth.

Recently, during on farm routine controls, carried out with fluorimetric spectroscopy [7], on on-farm produced feeds, it was

\footnotetext{
* Corresponding author. Tel.: +3906 49902764; fax: +390649387139.

E-mail address: g.brambi@iss.it (G. Brambilla).
}

found that corn seeds for pig nutrition were tetracycline contaminated (Fig. 1). Further analysis confirmed the presence of oxytetracycline at low ppm value. Such cross-contamination phenomena usually happen, at feed mill level, as consequence of medicated and not medicated feeds production on the same line [8].

In this case, the feed material was originated directly from the field; the question was whether the presence of tetracyclines could arise as a result of (i) soil dust contamination during harvesting or (ii) systematic absorption by plant roots from soil.

To deepen the matter, a pilot study was set up in the field, were corn was cultivated and fertilized with different slurries coming from OXY treated and untreated pigs.

\section{Experimentals}

Standards and reagents: oxytetracycline and its 4-epimer were purchased from Sigma-Aldrich Chemie Gmbh, Germany. Acetonitrile, and other chemicals were of the highest purity grade from Carlo Erba, Italy. Metal chelating sepharose fast flow was from Amersham Biosciences, UK; SPE box from Supelco. Rotary Evaporator (Buchii, Swiss), Ultrasonic bath, Bransonic 321 refrigerated centrifuge (Alc, Italy) and Beckmann Coulter 


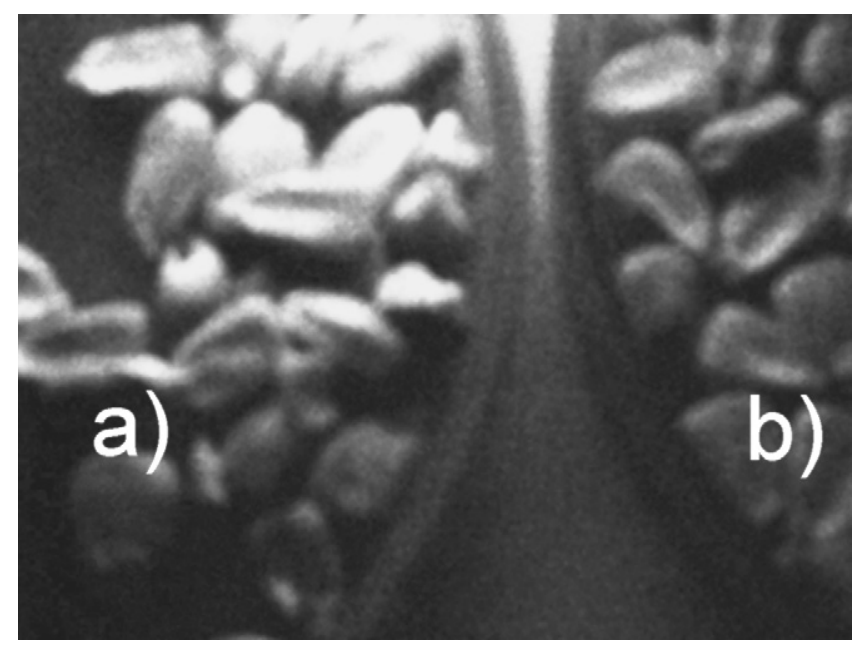

Fig. 1. Oxytetracycline contaminated (a) and control (b) Zea mays seeds intended for animal nutrition, at the direct fluorospectroscopic screening, under wood lamp.

high performance liquid chromatography (HPLC)-UV-DAD system gold were also used.

\subsection{Analyses}

Quantification of oxytetracycline (OXY) and/or its 4-epimer, in three different matrices was performed: (1) slurries from intensive swine farm from (i) weaning piglets, OXY medicated feeds administered, (ii) fattening pigs, no OXY medicated feed administration (as a total 14 samples: 6 weaning and 8 fattening); (2) soil from arable land used for Zea mays L. cultivation and a control site, collected from 0 to $40 \mathrm{~cm}$ depth of the land (as a total 12 samples: 6 from Reggio Emilia: cultivation, and 6 from Rome: control); (3) corn seeds coming from Zea mays grown on fields amended with contaminated and uncontaminated swine slurry (12 samples).

During extraction and purification procedures, samples were always saved in aluminium sheets and handled under dark, because of tetracyclines photodegradation.

\subsection{Extraction}

Liquid-liquid extraction, followed by Metal Chelate Affinity Chromatography (MCAC) was utilized to exploit tetracyclines propensity to bind metals [9]; the extraction procedure was very similar for each matrix considered.

\subsubsection{Slurry}

Ten grams of 6-month fermented slurry (from Davoli intensive swine farm; Reggio Emilia, Italy), were drawn under gentle agitation to allow the homogeneous distribution of the organic matter and poured into a $50 \mathrm{~mL}$ Falcon centrifuge tube. Citrate buffer (pH 4.7) $10 \mathrm{~mL}$, was then added and mixed thoroughly by vortexing and sonication $(15 \mathrm{~min})$. The fluid was then clarified on ALC $121 \mathrm{R}$ centrifuge $\left(8000 \times g, 20 \mathrm{~min},+4{ }^{\circ} \mathrm{C}\right)$ and the sediment re-extracted again with the addition of further $10 \mathrm{~mL}$ of citrate buffer. A second liquid-liquid extraction with $20+20 \mathrm{~mL}$ ethyl acetate, with vortexing and sonication $(5+5 \mathrm{~min})$, was performed. The organic upper layers were recovered, pooled together and dried up in rotary evaporator $\left(50^{\circ} \mathrm{C}\right)$ and then resuspended in $1 \mathrm{~mL}$ methanol, to be cleaned up on metal chelate affinity columns.

\subsubsection{Soil}

Ten grams soil, dry weight (from crop land belonging to Davoli farm, Reggio Emilia, Italy) was finely minced by crushing and with $20 \mathrm{~mL}$ citrate buffer ( $\mathrm{pH} 4.7)$ and further processed as described above.

\subsubsection{Corn seeds}

Ten gram seeds, dry weight (from Davoli farm, Reggio Emilia, Italy) were dried up, finely pulverized in homogenizer and extracted with the same procedure for soils.

All the operation were carried out avoiding the direct light, to prevent OXY photodegradation.

\subsection{Purification}

All samples were cleaned-up on metal chelate affinity chromatography (MCAC), as following. Empty $1 \mathrm{~mL}$ SPE cartridges were stopped on the bottom with a round glass fibre frit and then filled with $0.5 \mathrm{~mL}$ of chelating sepharose resin and posed on a SPE extractor. After washing with HPLC grade water, $(5 \mathrm{~mL})$ columns were conditioned with $1 \mathrm{~mL}$ of copper sulphate solution $0.1 \mathrm{M}$ and then $1 \mathrm{~mL} \mathrm{MeOH} / \mathrm{H}_{2} \mathrm{O}(1: 1, \mathrm{v} / \mathrm{v})$. Methanolic samples extracts were then loaded followed by $3 \mathrm{~mL}$ $\mathrm{MeOH} / \mathrm{H}_{2} \mathrm{O}$ and $2 \mathrm{~mL} \mathrm{H} \mathrm{H}_{2} \mathrm{O}$ washings. Elution of analyte was

Table 1

Mean recovery, repeatability $\left(\mathrm{CV}_{\mathrm{r}}\right)$ and reproducibility $\left(\mathrm{CV}_{\mathrm{R}}\right)$ of the analytical procedure with respect to the different matrices considered in the study

\begin{tabular}{|c|c|c|c|c|c|c|}
\hline Matrix & Spiking level $\left(\mathrm{ng} \mathrm{g}^{-1}\right)$ & 50 & 100 & 250 & 500 & 1000 \\
\hline \multirow{3}{*}{ Soil $(N=12)$} & Recovery (\%) & 87 & 85 & 87 & 86 & 87 \\
\hline & $\mathrm{CV}_{\mathrm{r}}$ & 3.3 & 2.8 & 2.6 & 2.5 & 2.7 \\
\hline & $\mathrm{CV}_{\mathrm{R}}$ & 4.0 & 3.5 & 3.5 & 3.3 & 3.6 \\
\hline \multirow{3}{*}{ Slurry $(N=12)$} & Recovery (\%) & 83 & 86 & 84 & 83 & 86 \\
\hline & $\mathrm{CV}_{\mathrm{r}}$ & 3.5 & 2.6 & 2.8 & 2.2 & 2.5 \\
\hline & $\mathrm{CV}_{\mathrm{R}}$ & 4.2 & 3.8 & 3.3 & 3.2 & 3.7 \\
\hline & $C V_{R}$ & 4.1 & 4.2 & 3.8 & 3.9 & 3.6 \\
\hline
\end{tabular}


achieved with the application of $2 \mathrm{~mL}$ McIlvaine solution ( $\mathrm{pH}$ 4.5). The first $\mathrm{mL}$ of eluate was collected in a HPLC autosampler vial, ready for HPLC determination. HPLC analysis was performed on the basis of the methods reported in the papers of Rupp [9] and Blanchflower [10]. A System Gold-Beckman HPLC system equipped with UV/DAD and autosampler was used with the following chromatographic conditions. Mobile phase: (A) glycine buffer $0.01 \mathrm{M} \mathrm{pH} \mathrm{7.6;} \mathrm{(B)} \mathrm{acetonitrile/water}$ $(8: 2$, v/v). Run: isocratic, $15 \% \mathrm{~B}$ for $5 \mathrm{~min}$; then, linear gradient to $40 \%$ B in $10 \mathrm{~min}$; column Purospher ${ }^{\circledR}$ STAR RP-C8 end capped (Lichrocart $250 \times 4 \mathrm{~mm}$ D.I., $5 \mu \mathrm{m}$ ); Flow rate: $1 \mathrm{~mL} \mathrm{~min}^{-1}$, loop $100 \mu \mathrm{L}$. For 4-epioxy determination, calibration curves were built in each matrix, spiking blank samples with the appropriate standard solution at level of 50, 100, 250, 500 and $1000 \mathrm{ng} \mathrm{g}^{-1}$ and let them rest overnight. The limit of detection was calculated on the basis of three times the signalto-noise ratio recorded in chromatograms from blank samples, at the retention time of the target analyte. Recovery rates were calculated against pure standard calibration curve. As quality control, in each analytical session, blank and $50 \mathrm{ng} \mathrm{g}^{-1}$ spiked samples were inserted in the procedure. Repeatability and reproducibility were assessed by analysing six replicates for each spiking level and matrix considered, on two different analytical sessions.

\section{Results}

\subsection{Analytical performances}

The limit of detection (Lod) on the basis of signal-to-noise ratio of control samples was estimated $20 \mathrm{ng} \mathrm{g}^{-1}$; the recoveries, along with repeatability $\left(\mathrm{CV}_{\mathrm{r}}\right)$ and reproducibility $\left(\mathrm{CV}_{\mathrm{R}}\right)$ data, resulted to be quantitative for all the matrices and the experimental points considered, with no significant mismatches (Table 1).

Results of the analyses of each incurred sample from contaminated and control series, respectively, are reported in Table 2. OXY residues were found in both slurries and soils; in soils they were at two orders of magnitude lower. Those samples showing an analyte concentration exceeding the maximum spiking level, were appropriately diluted to fall within the considered range of calibration. No detectable OXY residues were found in corn seeds. In Fig. 2 chromatograms of negative or positive soils, and negative corn are shown.

\section{Discussion}

Because OXY is excreted in faeces and urine also as 4-epimer, [11] and because such epimerisation is facilitated from $\mathrm{pH}$ environment around 6 [12], such as that in slurries and organically fertilised soils, the analytical strategy was addressed to transform the residual untransformed OXY in its 4-epimer. This was reached by storing the extracts in aqueous solution for more than 3 days at $-20^{\circ} \mathrm{C}$ [13]. The results of our trials confirm the environmental persistence of high oxytetracycline concentrations (at level of $\mu \mathrm{g} \mathrm{g}^{-1} 4$-epi-OXY) in slurries. Their strong binding with the organic matter through the formation

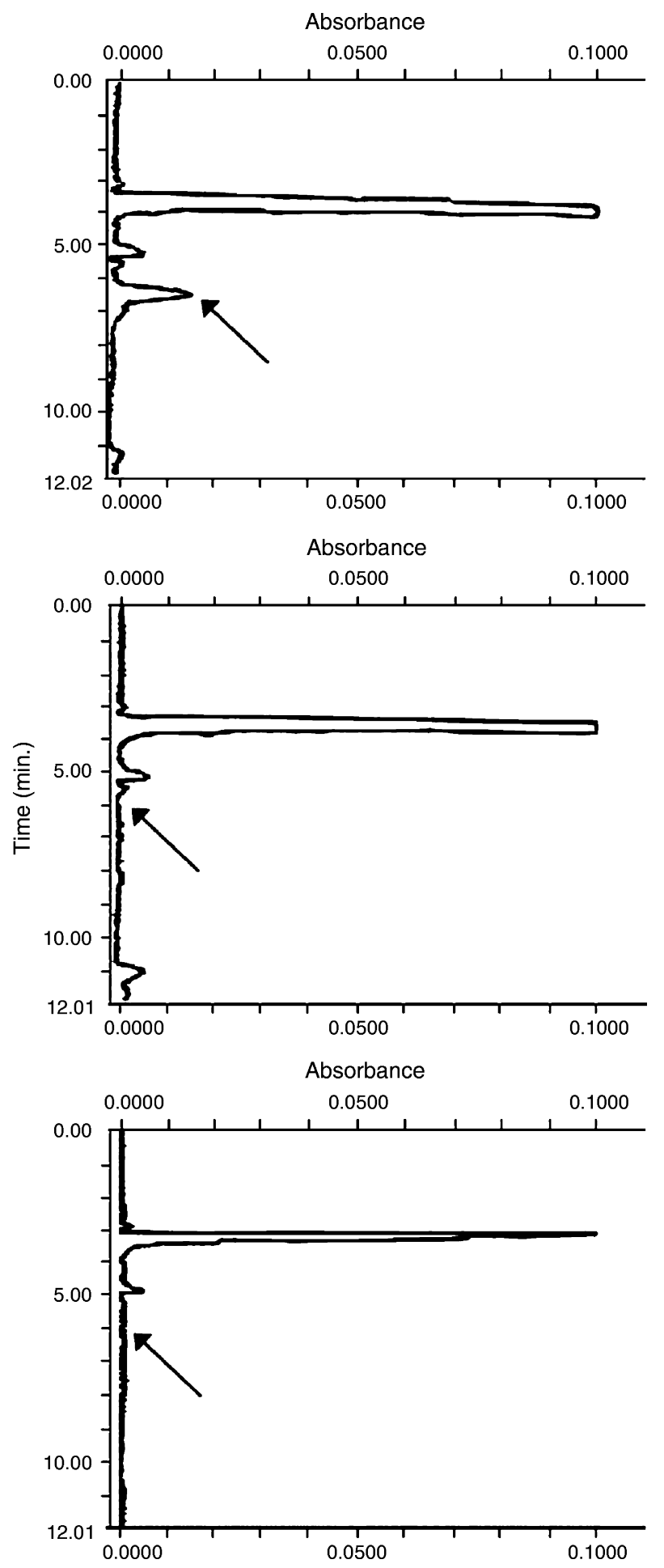

Fig. 2. From left to right, chromatograms of a contaminated soil, of a control soil, and of not contaminated mais seeds. The arrows indicate the 4-epi oxytetracycline retention time.

of metal bridging between the organic matter ligand groups and pharmaceutical ligand groups influences their presence and persistence in the bottom sediment of the lagoons, thus determining a carry-over also in slurries from fattening pigs fed on non medicated feeds (Table 2). Oxytetracycline transfer to soils by the use of slurries as a fertiliser has been also demonstrated, and soils efficiently bind such drug, according to their $\mathrm{pH}$, organic matter 
Table 2

Results of the analyses carried out on incurred samples, according to the experimental design

\begin{tabular}{|c|c|c|c|c|c|c|}
\hline \multirow[t]{2}{*}{ Sample } & \multicolumn{2}{|c|}{ Slurry ( $\mu g g^{-1} 4$-epi-OXY) } & \multicolumn{2}{|c|}{ Soil (ng g ${ }^{-1}$ 4-epi-OXY) } & \multicolumn{2}{|c|}{ Main seeds (ng g ${ }^{-1}$ 4-epi-OXY) } \\
\hline & Weaning pigs & Fattening pig & $\begin{array}{l}\text { Fertilised with } \\
\text { contaminated slurry }\end{array}$ & $\begin{array}{l}\text { Fertilised with } \\
\text { uncontaminated slurry }\end{array}$ & $\begin{array}{l}\text { From } \\
\text { contaminated soils }\end{array}$ & $\begin{array}{l}\text { From uncontaminated } \\
\text { soils }\end{array}$ \\
\hline 1 & 18 & 1 & 130 & $<20$ & $<20$ & $<20$ \\
\hline 2 & 25 & 1 & 216 & $<20$ & $<20$ & $<20$ \\
\hline 3 & 27 & 2 & 206 & $<20$ & $<20$ & $<20$ \\
\hline 4 & 29 & 3 & 157 & $<20$ & $<20$ & $<20$ \\
\hline 5 & 24 & 6 & 188 & $<20$ & $<20$ & $<20$ \\
\hline 6 & 22 & 5 & 127 & $<20$ & $<20$ & $<20$ \\
\hline 7 & - & 5 & - & - & - & - \\
\hline 8 & - & 8 & - & - & - & - \\
\hline Mean & 24 & 4 & 171 & - & - & - \\
\hline S.D. & 3 & 3 & 38 & - & - & - \\
\hline
\end{tabular}

content and presence of metals thus acting as possible abiotic reservoir. [14]

The levels of contamination we found in such compartment (ng g ${ }^{-1}$ ) (Table 2) seem not high enough to determine an appreciable contamination of seeds, as consequence of possible systemic absorption of drug, as already reported [13]. Nevertheless, the capability of different plants to absorb and store different antimicrobial drugs from different media [15-20] give risk concerns, and the possibility that some arable land could be more heavily contaminated as result of long-term fertilisation with pig slurries from intensive farming systems, should be not disregarded. To reduce possible environmental contamination of corn and/or other crop plants, the following management options could be suggested: reduction of the organic content matter of slurries, fraction to which antimicrobials binds, and dedicated lagoons for the storage of contaminated slurries, to be independently processed.

In conclusion, soil constitute abiotic reservoir for antimicrobial drugs and attention must be paid to prevent the systemic and/or external contamination of the forages.

\section{Acknowledgement}

Work supported by Regione Emilia Romagna grant, Assessorato alle Politiche Agricole e Ambientali: CRPA 2005 project.

\section{References}

[1] M.S. Diaz-Cruz, M.J. Lopez de Alda, D. Barcelo, Trends Anal. Chem. 22 (2003) 6 .
[2] M. De Liguoro, V. Cibin, F. Capolongo, B. Halling-Sørensen, C. Montesissa, Chemosphere 52 (2003) 203.

[3] P. Kay, P.A. Blackwell, A.B.A. Boxall, Chemosphere 60 (2005) 497.

[4] H. Aubry-Damon, K. Grenet, P. Sall-Ndiaye, D. Che, E. Cordeiro, M.E. Bougnoux, E. Rigaud, Y. Le Strat, V. Lemanissier, L. Armand-Lefevre, D. Delzescaux, J.C. Desenclos, M. Lienard, A. Andremont, Emerg. Infect. Dis. 10 (2004) 873.

[5] S. Thiele-Bruhn, I.C. Beck, Chemosphere 59 (2005) 457.

[6] C.R. Anderson, H.S. Rupp, W.H. Wu, J. Chrom. A 1075 (2005) 23.

[7] M.J. Schneider, S.J. Lehotay, JAOAC Int. 87 (2004) 587.

[8] J.D.G. McEvoy, Anal. Chim. Acta 473 (2002) 3.

[9] H.S. Rupp, C.R. Anderson, JAOAC Int. 88 (2005) 505.

[10] W.J. Blanchflower, R.J. McCracken, D.A. Rice, Analyst 114 (1989) 421.

[11] F. Capolongo, A. Santi, L. Tomasi, P. Anfossi, M. Missagia, C. Montesissa, JAOAC Int. 85 (2002) 8.

[12] M. Kuhne, D. Ihnen, G. Moller, O. Agthe, J. Vet. Med. A 47 (2000) 379.

[13] K. Kumar, S.C. Gupta, S.K. Baidoo, Y. Chander, C.J. Rosen, J. Environ. Qual. 34 (2005) 2082.

[14] T.L. ter Laak, A.G. Wouter Tolls, J. Environ. Toxicol. Chem. 25 (2006) 933

[15] L. Migliore, G. Brambilla, S. Cozzolino, L. Gaudio, Agricult. Ecosyst. Environ. 52 (1995) 103

[16] L. Migliore, G. Brambilla, P. Casoria, S. Cozzolino, C. Civitareale, L. Gaudio, Agricult. Ecosyst. Environ. 60 (1996) 121.

[17] L. Migliore, C. Civitareale, G. Brambilla, S. Cozzolino, P. Casoria, L. Gaudio, Agricult. Ecosyst. Environ. 65 (1997) 163.

[18] L. Migliore, S. Cozzolino, M. Fiori, Chemosphere 40 (2000) 741.

[19] C. Forni, A. Cascone, M. Fiori, L. Migliore, Water Res. 35 (2002) 1592.

[20] A. Cascone, C. Forni, L. Migliore, Water Air Soil Pollut. 156 (2004) 241 